\begin{tabular}{l} 
SCIENCE \& TECHNOLOGY \\
Journal homepage: http://www.pertanika.upm.edu.my/ \\
\hline PERTANIKA
\end{tabular}

\title{
Solution of Collinearity Problem in Two-Dimensional Electrical Resistivity Tomography using Wenner Array
}

\author{
Mustapha Adejo Mohammed ${ }^{1,2}$, Nordiana Mohd Muztaza ${ }^{1 *}$ and Rosli Saad ${ }^{1}$ \\ ${ }^{1}$ School of Physics, Universiti Sains Malaysia, 11800 Pulau Pinang, Malaysia \\ ${ }^{2}$ Department of Physics, Federal University of Lafia, Nasarawa, Nigeria
}

\begin{abstract}
Two-dimensional electrical resistivity tomography (2-D ERT) is one of the most common geophysical tools employed to satisfy the ever-growing need for obtaining subsurface information. Most of the conventional electrode arrays used for 2-D ERT survey are built with the theoretical assumption that the survey lines are straight to guarantee four collinear electrodes at every point of measurement. However, due to surface constraint associated with most survey areas, it is rarely possible to conduct a two-dimensional resistivity survey on a straight line. Therefore, 2-D ERT survey conducted on a surface constraint field requires shifting one or more electrodes off the survey line, which contrasts with the underlying assumption. Consequently, the result might be prone to false anomalies. Thus, this study aimed to device a new approach that could mitigate the false anomalies posed by noncollinearity of electrodes in 2-D ERT result. In view of this, ABEM Terrameter SAS4000 using Wenner array configuration was adopted for the survey. The data was acquired with all electrodes inline and one or more electrodes offline at stepwise distances, respectively. Based on the result obtained, the new approach mitigates the offline electrodes effect, as the inverse resistivity tomograms resolves the geometries of the true model reasonably well. More so, it has high R-value $>90 \%$ which is an indication of proximity to the true model. Hence, it is concluded that the new approach is effective in mitigating offline electrode effect on a 2-D ERT result.
\end{abstract}

ARTICLE INFO

Article history:

Received: 02 November 2020

Accepted: 19 February 2021

Published: 30 April 2021

DOI: https://doi.org/10.47836/pjst.29.2.27

E-mail addresses:

mustyadejo@gmail.com (Mustapha Adejo Mohammed),

mmnordiana@usm.my (Nordiana Mohd Muztaza)

rosli@usm.my (Rosli Saad)

* Corresponding author
Keywords: Collinear electrodes, mitigate, resistivity tomography, Wenner array

\section{INTRODUCTION}

The quest for subsurface information in environmental and engineering management had become paramount. This is due to 
the vital role the subsurface information plays in the design of civil structures to avoid foundation failure, which could lead to loss of lives and properties. More so, it plays an essential role in the delineation of groundwater potential zones to ensure optimum development and management of groundwater resources. Conventionally, a subsurface investigation is based on borehole exploration method (Anastasopoulos, 2013; Pando et al., 2013). However, the technique is attributed with several drawbacks such as high cost of drilling, limited data coverage, site damage and time-consuming. Therefore, to address these drawback, multidisciplinary research across the engineering, physical and social sciences is required (Fragaszy et al., 2011). Thus, geophysical methods offer solution to some of the inherent challenges in borehole exploration method (Abidin et al., 2017) Among the advantages of geophysical techniques are; fast data acquisition, low cost and ability to cover a large area (Cosenza et al., 2006; Godio et al., 2006)

As reported by Griffiths and Barker (1993), the electrical resistivity method is one of the most often used geophysical methods for subsurface investigation. Over time, the technique had witnessed great improvement in terms of availability of forward modelling and inversion schemes, efficient data acquisition and processing techniques (IngemanNielsen et al., 2016; Rucker et al., 2012). This led to the evolvement of two, three- and four-dimensional electrical resistivity tomography. However, the two-dimensional electrical resistivity tomography (2-D ERT) is the best choice when the goal is to keep survey cost down and obtain an accurate result. As such, the technique is widely employed in geophysical investigations involving subsurface characterization, hydrogeology, karst and cave finding, mineral exploration, geotechnical and archaeological prospecting (Abudeif et al., 2020; Loke et al., 2013; Uhlemann et al., 2018).

Furthermore, most of the electrode arrays such as Wenner, Wenner-Schlumberger, Dipole-dipole and Pole-dipole employed for 2-D ERT survey are designed with the assumption that the survey line is straight to ensure collinear electrode pairs at each point of measurement. But, due to surface constraint associated with most survey areas, it is rarely possible to conduct a two-dimensional resistivity survey on a straight line. To this end, Szalai et al. (2008) investigated the effect of electrode positioning error on the inverted pseudo-section of a 2-D ERT survey. They found the positioning error to be insignificant except for a very rocky field. And they suggested neglecting a few electrode positions with the greatest positioning error. In another work by Zhou and Dahlin (2003), they examined the properties and effect of measurement error (off-line and in-line spacing error) on 2-D resistivity tomography survey. In their study, the offline electrodes causing the offline spacing error were omitted. Hence, they concluded that the offline spacing error was negligible. However, ignoring or omitting some electrodes could generate false anomalies, thus leads to misinterpretation. 
This research, therefore, seeks to make known the effect of offline electrodes and develop a time and cost-effective approach that could mitigate the effect without ignoring or omitting any electrode. To achieve this, Wenner array was employed for the survey. The survey was conducted with all electrodes inline and some electrodes offline respectively, with the view to reveal the offline electrode effect. More so, the new approach attempted to recalculate the geometric factor and thus the apparent resistivity of those data points associated with the offline electrodes in an automated manner. The obtained result of this research will no doubt help to prevent misinterpretation caused by the offline electrodes on a 2-D ERT survey.

\section{MATERIALS AND METHODS}

\section{Description of Study Area and Geology}

The study area is located in Universiti Sains Malaysia, Penang Island, Malaysia. The area has a tropical climate with temperature ranging from $23.5^{\circ} \mathrm{C}$ to $31.4^{\circ} \mathrm{C}$, average annual rainfall from $2670 \mathrm{~mm}$ to $3250 \mathrm{~mm}$, and relative humidity ranging from $60.9 \%$ to 96.8 $\%$ (Ali et al., 2011). Geologically, the island is underlain by granitic rock (Figure. 1). The island is divided mainly into two groups: the North Penang Pluton (NPP) and the South Penang Pluton (SPP). The NPP consists of orthoclase to intermediate microcline granite, while the SPP is dominated by microcline granite (Ahmad et al., 2006; Tan, 1994). The study

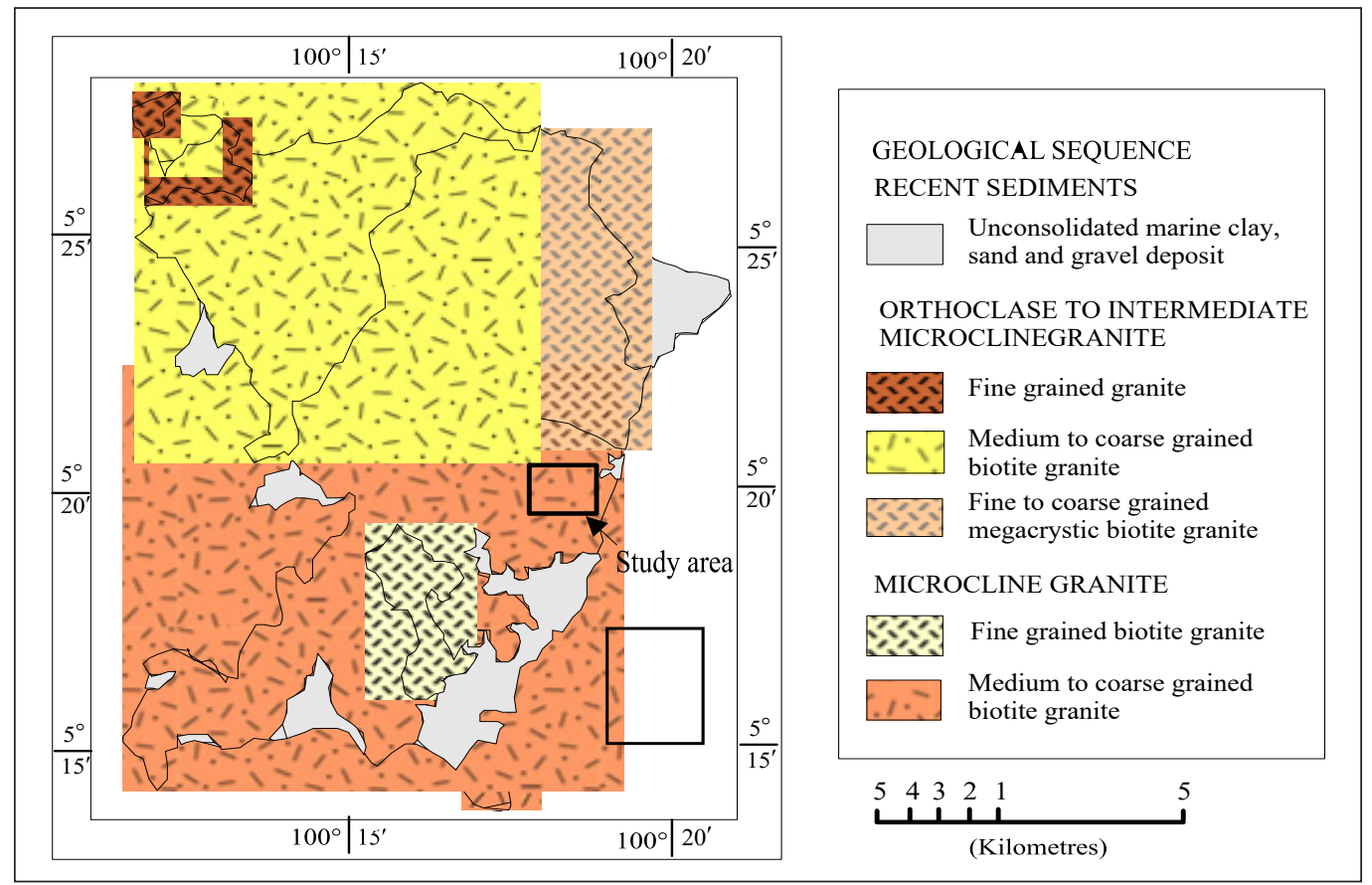

Figure 1. Geology map of Penang Island Malaysia showing the study area 
area belongs to the South Penang Pluton, which is of late Carboniferous age. The SPP is composed of fined grained biotite and medium to coarse-grained biotite granite (Ali et al., 2011; Pradhan \& Lee, 2010). Universiti Sains Malaysia (USM) consists mainly of residual soil originating from the parent rock; as such, it is relatively homogeneous in composition. This, therefore, reduces possible errors in our research as the geology is incomplex.

\section{Data Acquisition}

In general, a set of four electrodes were used for every measurement (Figure 2). The subsurface potential contrast (V) was measured between two electrodes (often called potential electrodes, indicated by $\mathrm{M}-\mathrm{N}$ ) upon injecting specified amount of electric current (I) into the ground between the other two electrodes (current electrodes, A-B). Since the principle of electrical resistivity method is embedded in Ohm's law, the resistance (R) is then computed using Equation 1 (Muhammad \& Saad, 2018). Subsequently, the apparent resistivity is obtained when array geometrical factor is known (Equation 2). The geometric factor $(K)$ is a key component in determining the apparent resistivity. Its value varies, depending on the type of array (i.e., geometric location of current and potential electrodes) used for the measurement.

$$
\begin{aligned}
& R=\frac{V}{I} \\
& \rho_{a}=K R
\end{aligned}
$$

And

$$
K=\frac{2 \pi}{\left(\frac{1}{r_{1}}-\frac{1}{r_{2}}-\frac{1}{r_{3}}+\frac{1}{r_{4}}\right)}
$$

where $r_{1}, r_{2}, r_{3}$ and $r_{4}$ are the inter-electrode distances (Equation 3).

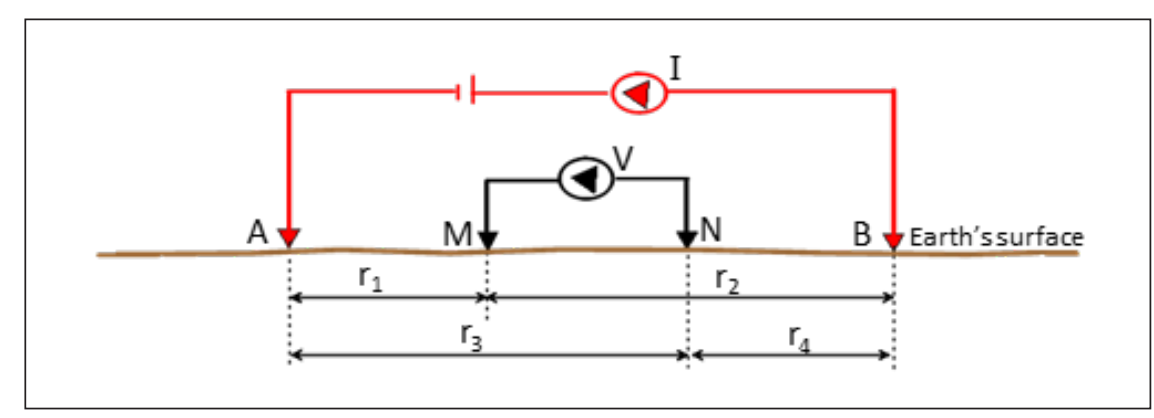

Figure 2. Four-point electrode configuration for Wenner array 
Multi-electrode resistivity meter (ABEM Terrameter SAS4000) was used to acquire the 2-D ERT survey data. Wenner Array was employed for this study due to its high signalto-noise ratio and sensitivity to vertical changes in resistivity (Dahlin \& Zhou, 2004; Loke, 2018) The data acquisition was in two phases, these are; survey with all electrodes inline and survey with one or more electrodes offline. In both phases, the input current was set between 1 and $100 \mathrm{~mA}$. The procedure involved for each phase is explained in the following subsection.

\section{Wenner Array with All Electrodes Inline}

(WA-AEI). Measurement was made on a 40 m-long profile with 41 stainless steel electrodes planted at $1 \mathrm{~m}$ minimum electrode spacing (Figure 3). All the multielectrodes were linearly planted to ensure the collinearity of electrodes pairs at each point of measurement, as stated theoretically (Loke et al., 2013). The measurement had a total of 260 data points. It is important to note that each electrode used for the measurement has a specified number of data points associated with it depending on its lateral position along the profile. More so, the WA-AEI survey was the true model.

\section{Wenner Array with One Or More Electrodes Offline (WA-1MEO). In this} phase, Wenner array was conducted with one, two and three electrodes offline (WA1EO, WA-2EO, and WA-3EO) respectively.

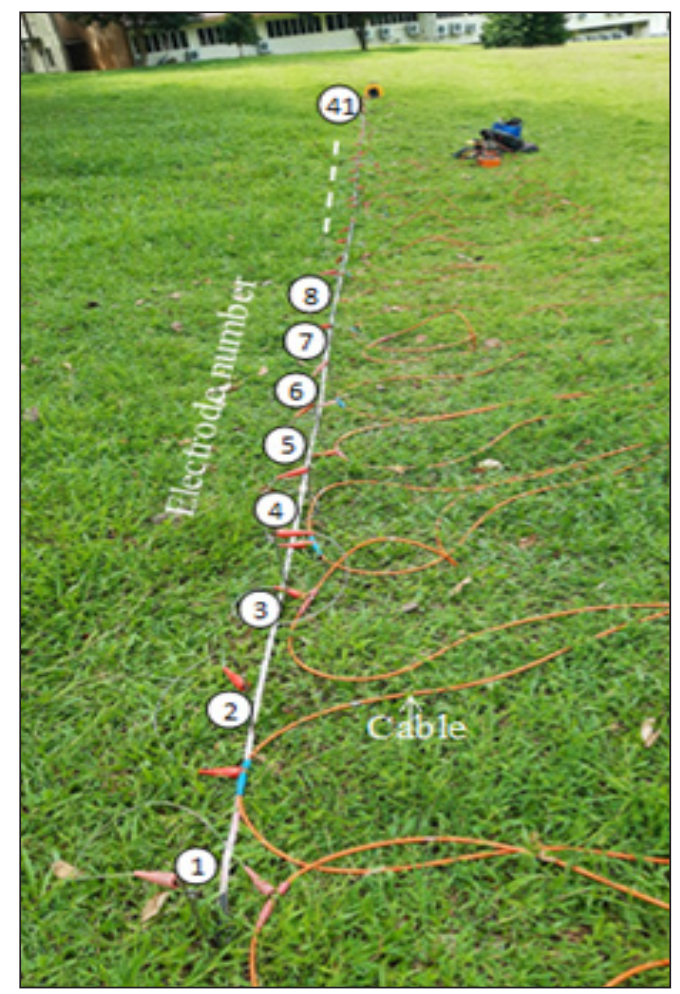

Figure 3. Site photos for a 2-D electrical resistivity tomography survey using Wenner array with all electrodes inline

\section{Figure 4 depicts survey site photos for WA-}

\section{$1 \mathrm{EO}, \mathrm{WA}-2 \mathrm{EO}$ and WA-3EO with offline}

electrode(s) at $1 \mathrm{~m}$ off the survey line. The choice for the selected electrodes offline was discretionary, with the view to observe the possible effect on the inverse resistivity model. In WA-1EO survey, the electrode arrangement used for WA-AEI was maintained (40 m-long profile) except electrode number 21 that was perpendicularly shifted off the survey line in a stepwise distance of $0.1 \mathrm{~m}$ increment $(0.1,0.2, \ldots 1.2 \mathrm{~m})$ for each acquisition. The shifted electrode (electrode number 21) was associated with 33 data points, and it implied that for all the measurements taken, 33 data points were affected for each increment. For WA-2EO 


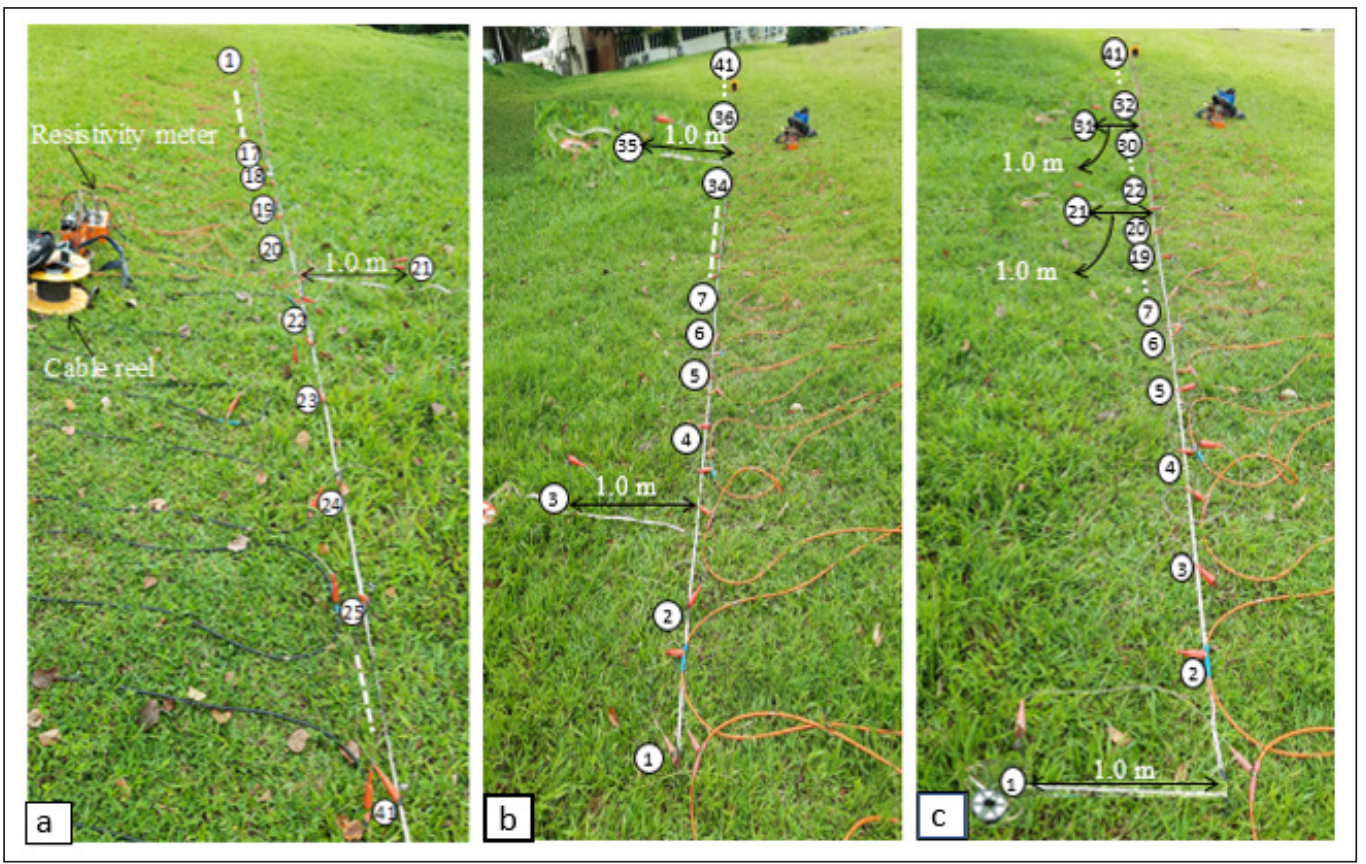

Figure 4. Site photos for a 2-D electrical resistivity tomography survey using Wenner array with (a) electrode number 21 offline (b) electrode number 3 and 35 offline and (c) electrode number 1, 21 and 31 offline at $1.0 \mathrm{~m}$ distance respectively

survey, all the electrodes used for WA-AEI measurement remained fixed (40 m-long profile) except electrodes number 3 and 35 that were orthogonally offline in a stepwise distance of $0.1 \mathrm{~m}$ increment $(0.1,0.2, \ldots 1.2 \mathrm{~m})$ for each measurement. As mentioned earlier, each electrode had a range of data points associated with it. A total of 37 data points associated with the two shifted electrodes were found to be affected for each acquisition.

In a similar vein, WA-3EO measurements were made along $40 \mathrm{~m}$-long profile as in WA-AEI, with 41 electrodes linearly planted except for electrodes $(1,21 \& 31)$ that were shifted perpendicularly off the 2-D resistivity survey line in a stepwise distance of $0.1 \mathrm{~m}$ increment $(0.1,0.2, \ldots 1.2 \mathrm{~m})$. Just like the previous phases, 68 data points were associated with these shifted electrodes. Therefore, 68 data points were affected in each of the measurements made for the respective increment.

\section{Data Processing}

The data was processed qualitatively and quantitatively. The qualitative assessment was done in two stages viz. using the conventional approach and a new approach. In the first stage, the conventional approach was built with the assumption of four collinear electrodes. Figure 5 depicts a typical scenario of four electrodes used to acquire the measurement at a time. Considering the four collinear electrodes (blue circles), the geometric factor 
for Wenner array is thus defined as in Equation 4 and was used throughout for the transformation. The conventional approach (ABEM Terrameter SAS4000 utilities software) was used to transform all the acquired data to the desired output format such as ABEM multi-purpose format (*.AMP) and Res2Dinv format (*.DAT) for further processing and analysis. Thereafter, Res2Dinv Geotomo software was used to perform inversion of the transformed resistivity data and Surfer 13 Golden software was later used to enhance the visualization of the inverse resistivity models. Considering the relative homogeneous nature of the study area, smoothness-constrained least-square inversion method was used (Loke et al., 2003; Loke \& Barker, 1996). The iterative inversion process was set at a maximum of five (5) iteration. For each iteration, the inversion tries to reduce the root mean squared (RMS) error in an effort to find a better model (Martínez-Moreno et al., 2013). However, a lower RMS error does not always equate to a better model, as more iteration tend to overfit the data.

$$
K_{W A}=2 \pi \frac{1}{\left(\frac{1}{A M}-\frac{1}{B M}-\frac{1}{A N}+\frac{1}{B N}\right)}
$$

where $A M, B M$, and $A N, B N$ represent the geometrical distance. The four inline electrodes are collinear, and the distance $A M, M N$ and $B N$ are all equal $A M=M N=B N=a$.

In the second stage, the new approach developed on Jupyter notebook environment using Python programing language was used to transform all the acquired data to Res2Dinv format (*.DAT) for further processing and analysis. Subsequent process is the same as in stage one above. The new approach was designed to account for the electrodes offline on a 2-D ERT survey. For instance, in Figure 5 above, consider electrode $N$ is shifted perpendicular to a new position say $X_{n}\left(A M \neq M X_{n} \neq B X_{n} \neq a\right)$, the theoretically assumed collinearity of electrodes in the conventional program is distorted, which in turn,

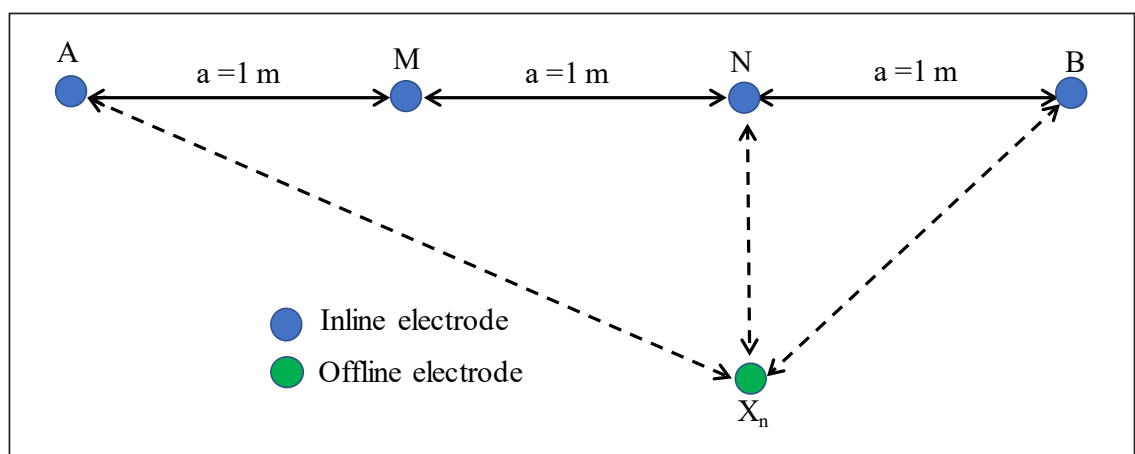

Figure 5. Typical scenario of four electrodes for measurement using Wenner array with electrodes inline (blue circle) and offline (green circle) arrangement 
affects the $K$ factor and, consequently, the apparent resistivity. Therefore, the geometric factor (Equation 4) defined above cannot hold. Hence, it must be modified as in Equation 5 and embedded in the template of the new approach. Basically, the new approach is a pre-processing template which enables the user to key in the offline electrodes and the offline distances thereby automatically recalculate the geometric factor and the apparent resistivity of the data points associated with the offline electrodes.

$$
\begin{aligned}
& K_{W A_{-} i}=2 \pi \frac{1}{\left(\frac{1}{A M}-\frac{1}{B M}-\frac{1}{A X_{n}}+\frac{1}{B X_{n}}\right)} \\
& A X_{n}=\left[(2 a)^{2}+\left(N X_{n}\right)^{2}\right]^{1 / 2} \\
& B X_{n}=\left[(2 a)^{2}+\left(N X_{n}\right)^{2}\right]^{1 / 2}
\end{aligned}
$$

Where $i=0.1,0.2,0.3, \ldots \ldots \ldots$ and $n=1,2,3, \ldots$

For the quantitative assessment, Pearson correlation coefficient (R) for the two phases was computed. The correlation coefficient $(R)$ provides a simple measure of the degree of linear correlation between two images (Abdullah et al., 2018). Its value ranges from -1 to +1 . An identical or close comparison of the desired target is obtained for R-value approaching +1 . $R$ can be computed using Equation 6 .

$$
R=\frac{N\left(\sum \rho_{t} \rho_{i}\right)-\left(\sum \rho_{t}\right)\left(\sum \rho_{i}\right)}{\sqrt{\left\{N \sum\left(\rho_{t}\right)^{2}-\left(\sum \rho_{t}\right)^{2}\right\}\left\{N \sum\left(\rho_{i}\right)^{2}-\left(\sum \rho_{i}\right)^{2}\right\}}}
$$

where; $\rho_{t}$ is the resistivity of the true model and $\rho_{i}$ is the resistivity of the estimated models, $N$ is the total number of data points.

\section{RESULTS AND DISCUSSION}

The result was presented qualitatively and quantitatively. The qualitative assessments involved the visual evaluation of the inverse resistivity contour plots produced by the conventional program and new approach for 2-D ERT using Wenner array with all electrodes inline (true model), one offline electrode, two offline electrodes, and three offline electrodes (estimated models). A comparison was made between the resistivity contour plots produced using the conventional program and the new approach. The measured resistivity obtained for all the profiles varied from 0 to $4000 \Omega-\mathrm{m}$. Six tomograms were considered in each case for the estimated model's (survey with one, two, and three electrode(s) offline). This became necessary in order to limit the number of displayed tomograms for better 
visualisation and comparison. Therefore, tomograms with even number $(0.2,0.4,0.6$, $0.8,1.0,1.2 \mathrm{~m}$ ) offline distances were considered. For the quantitative aspect, Pearson's correlation coefficient $(\mathrm{R})$ was assessed.

\section{Wenner Array with All Electrodes Inline (WA-AEI)}

Figure 6 shows the result obtained for 2-D ERT Wenner array survey with all multielectrodes inline using the conventional program. The inverse resistivity contour plot obtained after 5 iteration has RMS error of $8.7 \%$. It indicated high resistivity zone $(>900$ $\Omega-\mathrm{m})$ within 0 to $4 \mathrm{~m}$ depth and low resistivity zone $(<900 \Omega-\mathrm{m})$ at depths greater than $4 \mathrm{~m}$, which is in conformity with the findings of (Muhammad \& Saad, 2018). The high resistivity zone defines the dry top residual soil which extends from the surface to a thickness of 4 $\mathrm{m}$, whereas, the low resistivity zone corresponds to the residual soil saturated with water (Abdulrahman et al., 2016). It is important to note that only the conventional program was used to process the WA-AEI data because the theoretical assumption of collinear electrode pairs was achieved. Therefore, the inverse contour plot obtained for WA-AEI serves as the true model for which the other survey profiles with electrodes offline are compared to observe the effect of the electrodes offline.

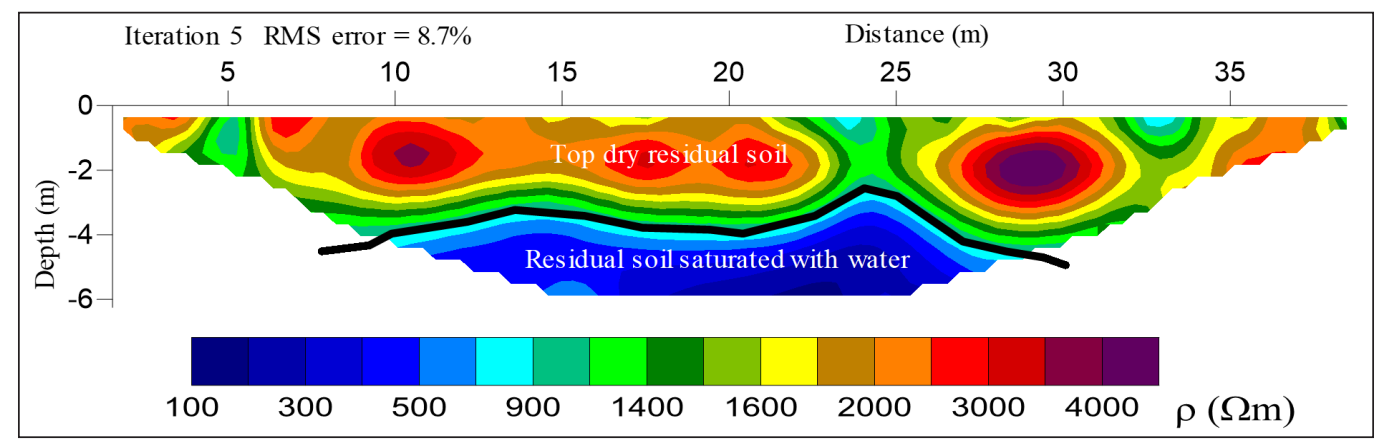

Figure 6. Two-dimensional resistivity contour plot for the true model

\section{Wenner Array with One Electrode Offline (WA-1EO)}

Prior to the inversion of the data, the percentage changes in the apparent resistivity due to the offline electrodes for the conventional and new approaches for WA-1EO, WA-2EO and WA-3EO is presented in Table 1. It is observed that the percentage change is directly proportional to the offline electrodes distance.

Figure 7 depicts juxtaposed two-dimensional tomograms for the true model and resistivity profiles with one electrode been offline at $0.2 \mathrm{~m}$ interval using the conventional approach and a newly developed approach. All the tomograms show fairly good result after five iteration of the inversion with RMS error ranging from $8.7 \%$ to $9.0 \%$. They depict high resistivity zone ( $>900 \Omega-\mathrm{m})$ at a depth of 0 to $4 \mathrm{~m}$ and low resistivity $(<900 \Omega-\mathrm{m})$ at a 
Table 1

Summary of percentage change in apparent resistivity due to offline electrode for WA-1EO, WA-2EO and WA-3EO using conventional and new approaches

\begin{tabular}{lccc}
\hline \multirow{2}{*}{ Offline electrode distance $(\mathrm{m})$} & \multicolumn{3}{c}{$\%$ change in apparent resistivity } \\
\cline { 2 - 4 } & WA-1ES & WA-2ES & WA-3ES \\
\hline 0.10 & 0.08 & 0.09 & 0.12 \\
0.20 & 0.33 & 0.34 & 0.45 \\
0.30 & 0.71 & 0.74 & 1.02 \\
0.40 & 1.22 & 1.97 & 1.83 \\
0.50 & 1.82 & 2.29 & 2.61 \\
0.60 & 2.50 & 3.01 & 3.52 \\
0.70 & 3.22 & 4.58 & 4.66 \\
0.80 & 3.98 & 4.09 & 5.33 \\
0.90 & 4.75 & 5.20 & 6.86 \\
1.00 & 5.53 & 6.64 & 7.47 \\
1.10 & 6.32 & 7.99 & 9.08 \\
1.20 & 7.09 & 8.07 & 9.74 \\
\hline
\end{tabular}

depth greater than $4 \mathrm{~m}$. The tomograms produced using the conventional approach for the models with one offline electrode nearly match the true model except for a few instances (Figure 7e-g) that shows a very slight variation of anomalies. This close match of the tomograms is a consequence of the high signal-to-noise ratio of the array (Cubbage et al., 2017; Thabit \& Khalid, 2016), whereas, the slight variation is likely due to the increase in offline electrode distance. However, the geometries of the true model are well resolved in all the tomograms obtained by using the new approach as shown in Figure $7 b^{\prime}-g^{\prime}$.

\section{Wenner Array with Two Electrodes Offline (WA-2EO)}

The juxtaposed tomographic images for the WA-AEI and WA-2EO at offline distances of $0.2,0.4,0.6,0.8,1.0$, and $1.2 \mathrm{~m}$ using the conventional approach and newly developed approach are shown in Figure 8. All the tomograms obtained for the WA-2EO models using the conventional approach indicated high $(>900 \Omega-\mathrm{m})$ and low $(<900 \Omega-\mathrm{m})$ resistivity zones at depths below and above $4 \mathrm{~m}$, respectively (Muhammad \& Saad, 2018). The geometries of the true model are partially resolved in all the images of WA-2EO. It is observed that the tomograms (Figure 8b-c) give a close replica to the true model, while the remaining images (Figure $8 \mathrm{~d}-\mathrm{g}$ ) produced by the survey (WA-2EO) with offline electrodes greater than $1 / 2$ of the minimum electrode spacing $(a)$ indicates a slight variation of anomalies when compared to the true model (Figure 8a). This shows that the greater the offline electrode distance the more the effect. This outcome is contrary to that of Szalai et al. (2008), who found that offline electrodes effect on 2-D ERT result was insignificant. More so, the low resistivity zone or saturated zone along the distance $(12 \mathrm{~m}-27 \mathrm{~m})$ at a depth of $4 \mathrm{~m}$ and 


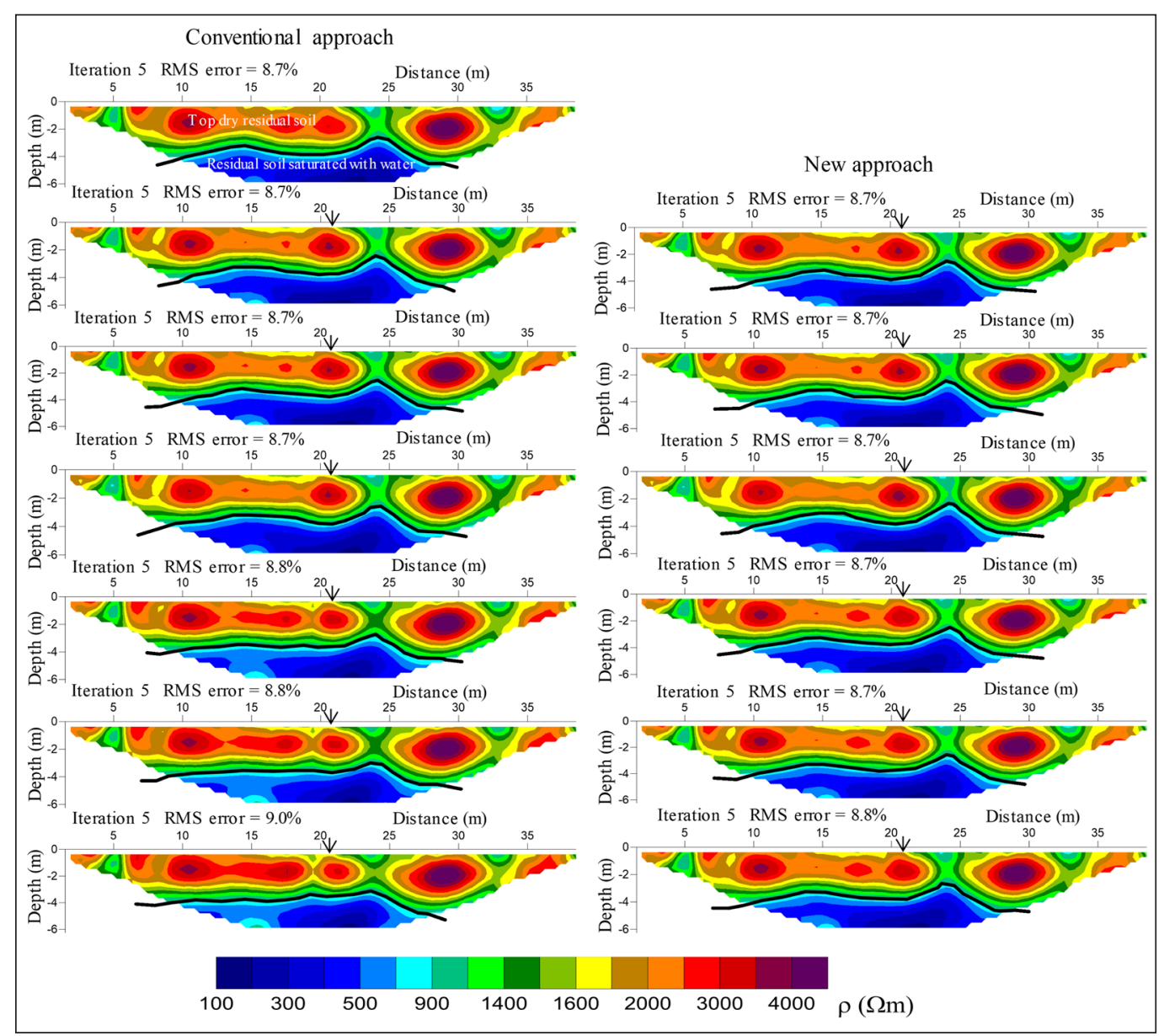

Figure 7. Two-dimensional resistivity contour plots comparison between (a) true model, and estimated models using conventional program and new approach for Wenner array with one electrode offline (WA-1EO) at (b/b') $0.2 \mathrm{~m},\left(\mathrm{c} / \mathrm{c}^{\prime}\right) 0.4 \mathrm{~m},\left(\mathrm{~d} / \mathrm{d}^{\prime}\right) 0.6 \mathrm{~m},\left(\mathrm{e} / \mathrm{e}^{\prime}\right) 0.8 \mathrm{~m},\left(\mathrm{f} / \mathrm{f}^{\prime}\right) 1.0 \mathrm{~m},(\mathrm{~g} / \mathrm{g}$ ') $1.2 \mathrm{~m}$ distances, respectively. The arrow sign indicates the position of the offline electrode

beyond (Figure $8 \mathrm{a}$ ), decrease to $13 \mathrm{~m}-24 \mathrm{~m}$ for WA- 2EO survey at $1.2 \mathrm{~m}$ offline electrodes distance (Figure 8g). Since the geology of the study area is relatively homogeneous, this variation of anomalies is attributed to the offline electrodes ( 3 and 35) and its corresponding distance of which the conventional approach cannot account for.

However, the limitation of the conventional approach which underestimated the anomaly for survey with electrodes offline has been demonstrated by the tomograms produced using the newly developed approach (Figure $8 b^{\prime}-g^{\prime}$ ). It is observed that the resistivity contour plots produced using the new approach fairly resolved the geometries of the true model than that of the conventional approach. This suggests that the newly developed approach can mitigate the false anomaly posed by offline electrode on a 2-D ERT survey. 


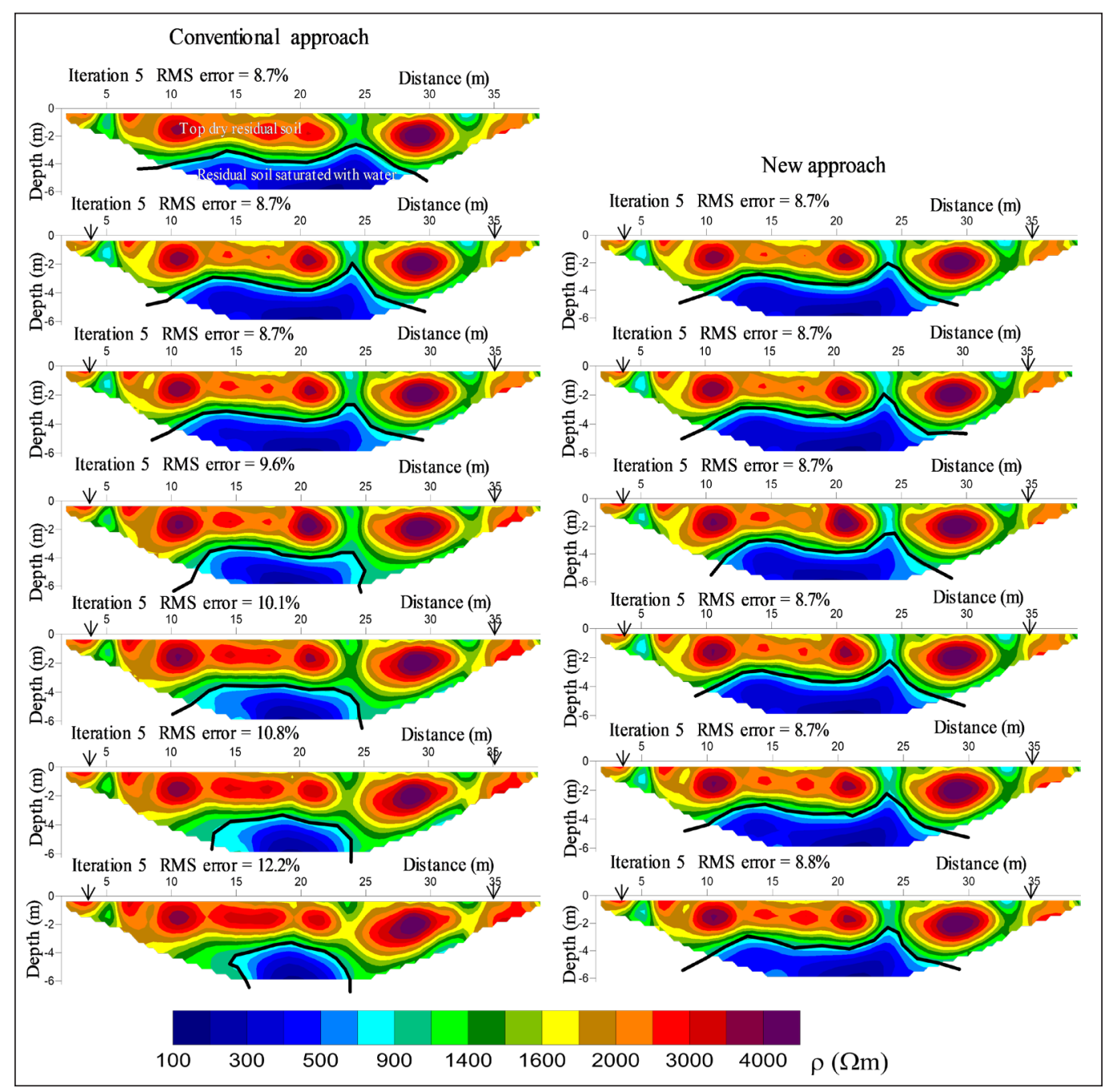

Figure 8. Two-dimensional resistivity contour plots comparison between (a) true model, and estimated models using conventional program and new approach for Wenner array with two electrodes offline (WA-2EO) at (b/b') $0.2 \mathrm{~m},\left(\mathrm{c} / \mathrm{c}^{\prime}\right) 0.4 \mathrm{~m},\left(\mathrm{~d} / \mathrm{d}^{\prime}\right) 0.6 \mathrm{~m},\left(\mathrm{e} / \mathrm{e}^{\prime}\right) 0.8 \mathrm{~m},\left(\mathrm{f} / \mathrm{f}^{\prime}\right) 1.0 \mathrm{~m},(\mathrm{~g} / \mathrm{g}$ ') $1.2 \mathrm{~m}$ distances, respectively. The arrow sign indicates the position of the offline electrodes

\section{Wenner Array with Three Electrodes Offline (WA-3EO)}

Figure 9 shows the tomographic images for the true model and resistivity profiles taken with three electrodes offline (WA-3EO) at distances of $0.2,0.4,0.6,0.8,1.0$, and $1.2 \mathrm{~m}$ using the conventional approach and the newly developed approach. The range of the resistivity values obtained is similar to those of WA-1EO and WA-2EO tomograms. However, the tomograms obtained for WA-3EO after the predefine iteration, has high RMS error $(10.1 \%$ to $18.2 \%$ ) particularly those obtained using the conventional approach. These set of tomograms also show distinct variation of anomalies when compared to the true resistivity 


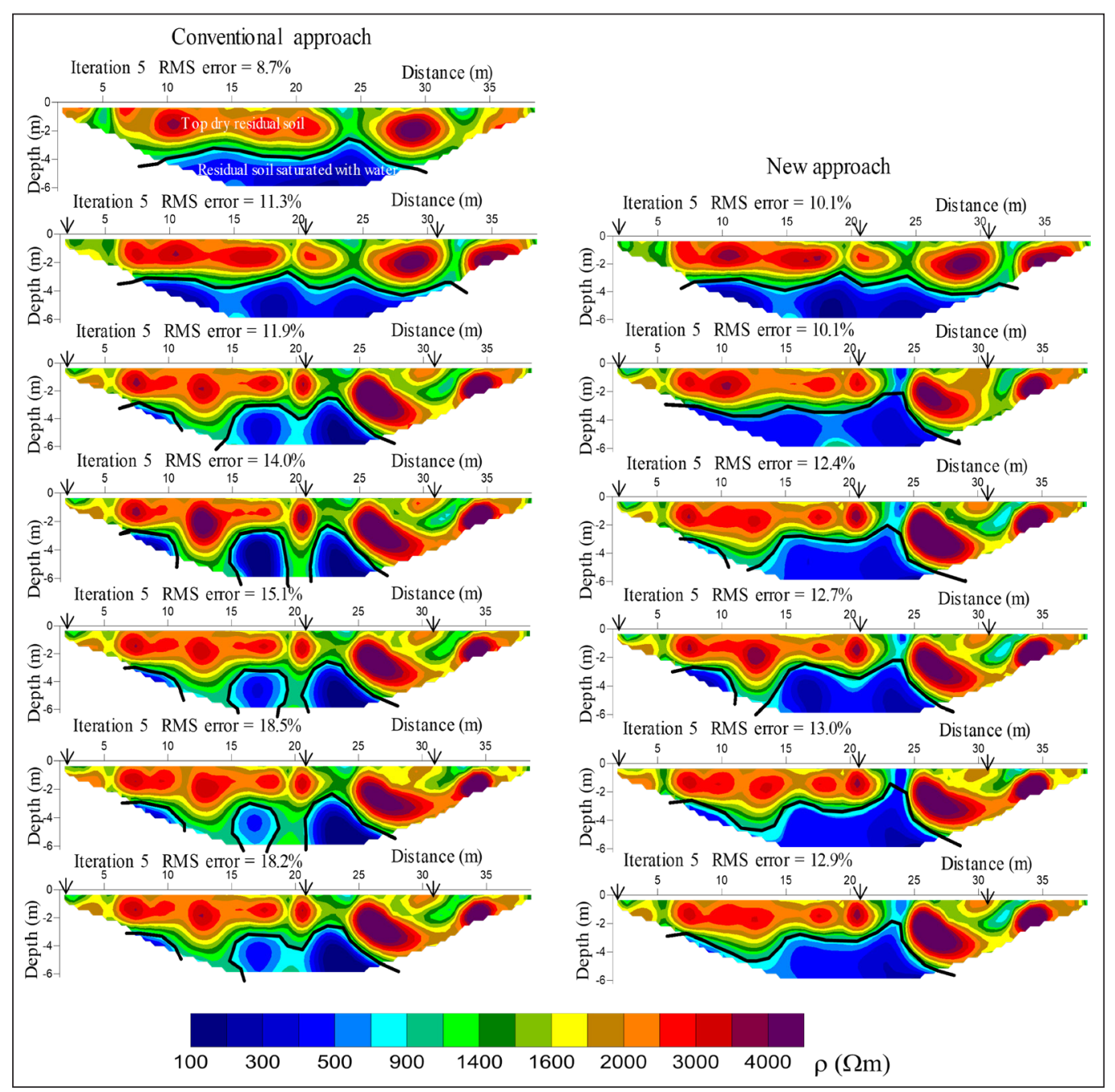

Figure 9. Two-dimensional resistivity contour plots comparison between (a) true model, and estimated models for Wenner array using conventional program and new approach with three electrodes offline (WA-3EO) at (b/b') $0.2 \mathrm{~m},\left(\mathrm{c} / \mathrm{c}^{\prime}\right) 0.4 \mathrm{~m},\left(\mathrm{~d} / \mathrm{d}^{\prime}\right) 0.6 \mathrm{~m},\left(\mathrm{e} / \mathrm{e}^{\prime}\right) 0.8 \mathrm{~m},\left(\mathrm{f} / \mathrm{f}^{\prime}\right) 1.0 \mathrm{~m},\left(\mathrm{~g} / \mathrm{g}^{\prime}\right) 1.2 \mathrm{~m}$ distances respectively. The arrow sign indicates the position of the offline electrodes

model. For instance, the highly saturated zone $(<900 \Omega-\mathrm{m})$ for the true model (Figure $9 \mathrm{a})$ which span from a distance of $12 \mathrm{~m}-27 \mathrm{~m}$ at the bottom part of the tomogram (depth $>4$ $\mathrm{m}$ ) appears to split into two for almost all the tomograms (Figure 9b-g). This is probably due to the distance of the electrodes offline and a large number of data point (one-quarter of the total dataset) associated with the three electrodes offline, as the geology of the study area is relatively homogeneous. This outcome differs from the findings of Szalai et al. (2008) and Zhou and Dahlin (2003), who found that offline electrodes had insignificant effect on electrical resistivity tomography result. 
Figure $9 b^{\prime}-g^{\prime}$ depicts the tomograms obtained for Wenner array with three electrodes offline using the newly developed approach. The tomograms illustrate some level of match when compared to the true model (Figure 9a). However, it does not resolve the geometries of the true model well, as it present a slanted high resistivity section that extent from 24 $\mathrm{m}$ to $37 \mathrm{~m}$ contrary to the true model. This is likely due to the large number $(26 \%)$ of contaminated data point involved. Comparing the tomograms produced by both approaches as juxtaposed in Figure 9, illustrated the effectiveness of the new approach in resolving the geometries of the true model. Hence, using the new approach in pre-processing a resistivity survey data with electrodes offline could significantly enhance the result, as it reduces the false anomalies introduced due to the electrodes offline.

In the quantitative assessment, the variation of the estimated models (WA-1EO, WA2EO, and WA-3EO) from the true model (WA-AEI) was carried out. Pearson's correlation coefficient $(\mathrm{R})$ of the estimated models using the conventional program and new approach was computed as presented in Tables 2, 3 and 4. The R-values obtained for processing with the new approach was appreciably high $(0.957-0.963,0.932-0.962$ and $0.470-0.753$ for WA-1EO, WA-2EO, and WA-3EO models respectively) as compared to that obtained for processing with conventional program (Table 2 - 4). This signifies that $95 \%-96 \%$, $93 \%-96 \%$, and $47 \%-75 \%$ of correlation is achieved between the true and the estimated models (WA-1EO, WA-2EO, and WA-3EO), respectively for the new approach. Based on the established fact, $\mathrm{R}$ value approaching +1 gives an identical or close approximation to the desired true model (Abdullah et al., 2018). Hence, the R value obtained for WA-1EO, WA-2EO, and WA-3EO using the new approach suggest proximity to the true model than

Table 2

Summary of Pearson's correlation coefficient between the conventional program (Conv) and new approach (NApp) for Wenner array with one electrode offline (WA-1EO)

\begin{tabular}{cccc}
\hline \multirow{2}{*}{ Number of profiles } & Offline electrode distance $(\mathrm{m})$ & \multicolumn{2}{c}{ Pearson correlation coefficient } \\
\cline { 3 - 4 } 1 & 0.1 & WA-1EO-Conv & WA-1EO-NApp \\
\hline 2 & 0.2 & 0.9627 & 0.9628 \\
3 & 0.3 & 0.9613 & 0.9623 \\
4 & 0.4 & 0.9593 & 0.9627 \\
5 & 0.5 & 0.9579 & 0.9634 \\
6 & 0.6 & 0.9527 & 0.9630 \\
7 & 0.7 & 0.9346 & 0.9575 \\
8 & 0.8 & 0.9257 & 0.9595 \\
9 & 0.9 & 0.9108 & 0.9583 \\
10 & 1.0 & 0.9023 & 0.9601 \\
11 & 1.1 & 0.8953 & 0.9612 \\
12 & 1.2 & 0.8772 & 0.9596 \\
\hline
\end{tabular}


using the conventional approach. This is clearly demonstrated in the graph for each table as shown in Figure 10. It is observed that as the offline electrode(s) distance increases beyond half the minimum electrode spacing, the R-value decreases, particularly when using the conventional program and for WA-3EO (Figure 10a-c). Therefore, the quantitative assessment has further revealed the efficacy of the new approach.

\section{Table 3}

Summary of Pearson's correlation coefficient between the conventional program (Conv) and new approach (NApp) for Wenner array with two electrodes offline (WA-2EO)

\begin{tabular}{cccc}
\hline \multirow{2}{*}{ Number of profiles } & Offline electrode distance $(\mathrm{m})$ & \multicolumn{2}{c}{ Pearson correlation coefficient } \\
\cline { 3 - 4 } & & WA-2EO-Conv & WA-2EO-NApp \\
\hline 1 & 0.1 & 0.9598 & 0.9598 \\
3 & 0.2 & 0.9618 & 0.9620 \\
4 & 0.3 & 0.9600 & 0.9537 \\
5 & 0.4 & 0.9615 & 0.9625 \\
6 & 0.5 & 0.9428 & 0.9447 \\
7 & 0.6 & 0.8932 & 0.9374 \\
8 & 0.7 & 0.8802 & 0.9345 \\
9 & 0.8 & 0.8824 & 0.9332 \\
10 & 0.9 & 0.8689 & 0.9336 \\
11 & 1.0 & 0.8511 & 0.9326 \\
12 & 1.1 & 0.8441 & 0.9343 \\
& 1.2 & 0.7912 & 0.9349 \\
\hline
\end{tabular}

Table 4

Summary of Pearson's correlation coefficient between the conventional program (Conv) and new approach (NApp) for Wenner array with three electrodes offline

\begin{tabular}{cccc}
\hline \multirow{2}{*}{ Number of profiles } & Offline electrode distance $(\mathrm{m})$ & \multicolumn{2}{c}{ Pearson correlation coefficient } \\
\cline { 3 - 4 } & & WA-3EO-Conv & WA-3EO-NApp \\
\hline 2 & 0.1 & 0.7247 & 0.7535 \\
3 & 0.2 & 0.7083 & 0.7449 \\
4 & 0.3 & 0.7118 & 0.7469 \\
5 & 0.4 & 0.7227 & 0.7467 \\
6 & 0.5 & 0.6938 & 0.7076 \\
7 & 0.6 & 0.6088 & 0.7008 \\
8 & 0.7 & 0.5959 & 0.6756 \\
9 & 0.8 & 0.5092 & 0.6341 \\
10 & 0.9 & 0.4300 & 0.6039 \\
11 & 1.0 & 0.3336 & 0.5872 \\
12 & 1.1 & 0.2805 & 0.4901 \\
& 1.2 & 0.2133 & 0.4706 \\
\hline
\end{tabular}




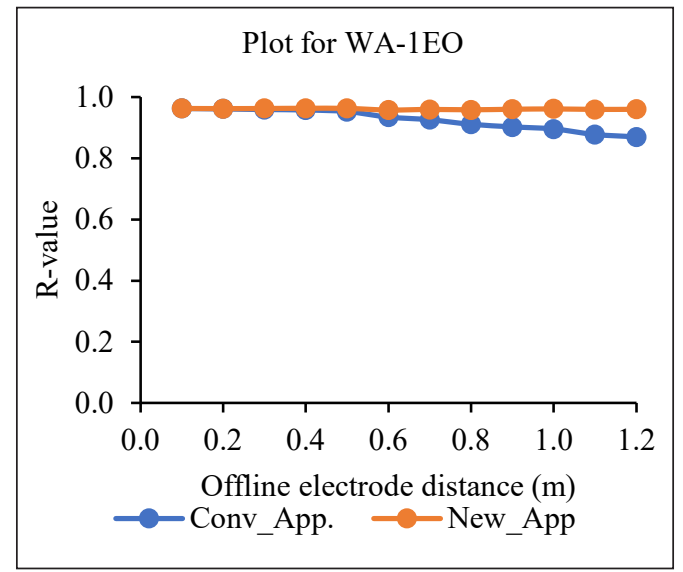

(a)

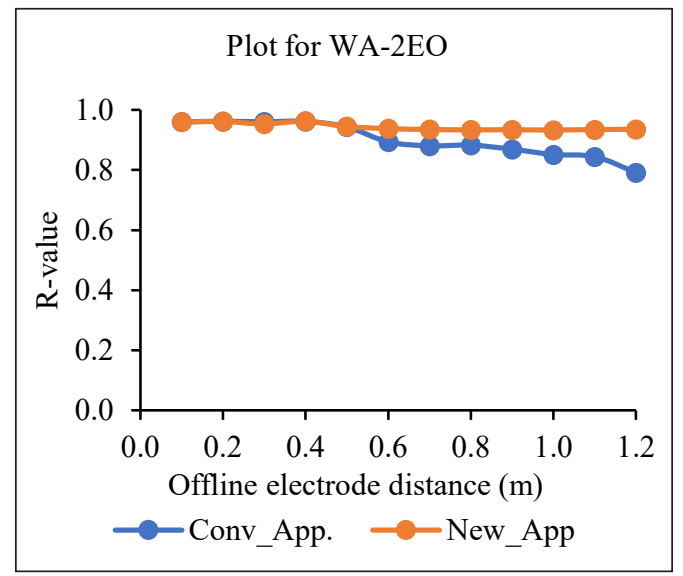

(b)

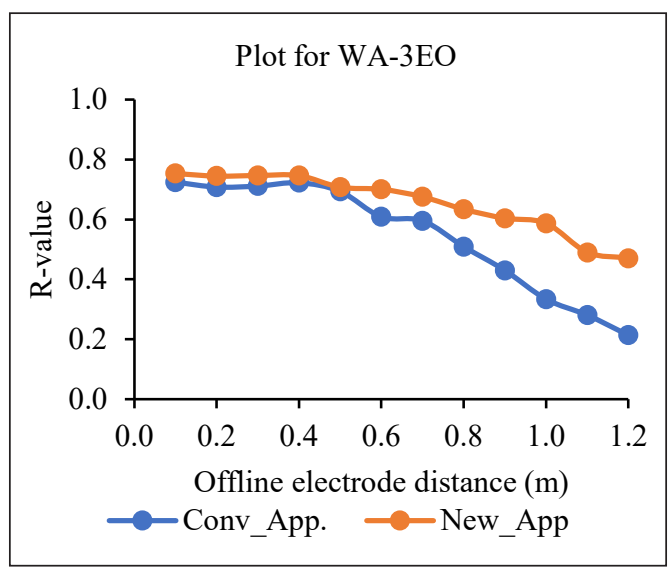

(c)

Figure 10. Graphs showing the variation of Pearson's correlation with offline electrode distance for (a) WA-1EO (b) WA-2EO and (c) WA-3EO

\section{CONCLUSION}

In this study, we proposed a new approach to enhance a 2-D ERT survey result by mitigating the effect of electrodes offline. The resistivity contour plots assessment performed between the true (WA-1EO) and the estimated models (WA-1EO, WA-2EO and WA-3EO) using the new approach, revealed insignificant variation of anomalies for all the estimated models. More so, most of the $\mathrm{R}$ values for the new approach is approaching +1 which demonstrated a close comparison to the true model. However, using the conventional program, the resistivity contour plots produced for WA-2EO and WA-3EO surveys showed slight to distinct variation of anomalies and the R value was relatively low (20\%) as compared to that of the new approach $>90 \%$. This variation of anomalies obtained using the conventional program could misguide the environmental and engineering experts in their structural 
design, thereby leading to collapse of structures, loss of lives and properties. Therefore, the study has proven the efficacy of the new approach in mitigating the effect posed by offline electrodes on a two-dimensional electrical resistivity tomography result.

\section{ACKNOWLEDGEMENT}

We would like to thank the technical staff and all our colleagues, Geophysics Section, School of Physics, Universiti Sains Malaysia (USM), for their help during the data acquisition. The authors wish to thank USM for providing the Fundamental Research Grant Scheme entitled Development of 2-D Linear Inversion Algorithm from Geophysical Approach for Soil or Rock Characteristics (203/PFIZIK/6711663). The first author expresses appreciation to the Federal University of Lafia and Tertiary Education Trust Fund (TetFund), Nigeria, for financial support.

\section{REFERENCES}

Abdullah, F. M., Loke, M. H., Nawawi, M., \& Abdullah, K. (2018). Assessing the reliability and performance of optimized and conventional resistivity arrays for shallow subsurface investigations. Journal of Applied Geophysics, 155, 237-245. https://doi.org/10.1016/j.jappgeo.2018.06.018

Abdulrahman, A., Nawawi, M., Saad, R., Abu-Rizaiza, A. S., Yusoff, M. S., Khalil, A. E., \& Ishola, K. S. (2016). Characterization of active and closed landfill sites using 2D resistivity/IP imaging: Case studies in Penang, Malaysia. Environmental Earth Sciences, 75(4), Article 347. https://doi.org/10.1007/s12665-015-5003-5

Abidin, M. H. Z., Madun, A., Tajudin, S. A. A., \& Ishak, M. F. (2017). Forensic assessment on near surface landslide using electrical resistivity imaging (ERI) at Kenyir Lake area in Terengganu, Malaysia. Procedia Engineering, 171, 434-444. https://doi.org/10.1016/j.proeng.2017.01.354

Abudeif, A. M., Mohammed, M. A., Fat-Helbary, R. E., El-Khashab, H. M., \& Masoud, M. M. (2020). Integration of $2 \mathrm{D}$ geoelectrical resistivity imaging and boreholes as rapid tools for geotechnical characterization of construction sites: A case study of New Akhmim city, Sohag, Egypt. Journal of African Earth Sciences, 163, Article 103734. https://doi.org/10.1016/j.jafrearsci.2019.103734

Ahmad, F., Yahaya, A. S., Farooqi, M. A., \& Tebal, N. (2006). Characterization and geotechnical properties of penang residual soils with emphasis on landslides. American Journal of Environmental Sciences, 2(4), 121-128.

Ali, M. M., Ahmad, F., Yahaya, A. S., \& Farooqi, M. A. (2011). Characterization and hazard study of two areas of Penang Island, Malaysia. Human and Ecological Risk Assessment: An International Journal, 17(4), 915-922. https://doi.org/10.1080/10807039.2011.588156

Anastasopoulos, I. (2013). Building damage during nearby construction: Forensic analysis. Engineering Failure Analysis, 34, 252-267. https://doi.org/10.1016/j.engfailanal.2013.08.003

Cosenza, P., Marmet, E., Rejiba, F., Cui, Y. J., Tabbagh, A., \& Charlery, Y. (2006). Correlations between geotechnical and electrical data: A case study at Garchy in France. Journal of Applied Geophysics, 60(34), 165-178. https://doi.org/10.1016/j.jappgeo.2006.02.003 
Cubbage, B., Noonan, G. E., \& Rucker, D. F. (2017). A modified Wenner array for efficient use of eightchannel resistivity meters. Pure and Applied Geophysics, 174(7), 2705-2718. https://doi.org/10.1007/ s00024-017-1535-9

Dahlin, T., \& Zhou, B. (2004). A numerical comparison of 2D resistivity imaging with 10 electrode arrays. Geophysical Prospecting, 52(5), 379-398. https://doi.org/10.1111/j.1365-2478.2004.00423.x

Fragaszy, R. J., Santamarina, J. C., Amekudzi, A., Assimaki, D., Bachus, R., Burns, S. E., Cha, M., Cho, G. C., Cortes, D. D., Dai, S., Espinoza, D. N., Garrow, L., Huang, H., Jang, J., Jung, J. W., Kim, S., Kurtis, K., Lee, C., Pasten, C., ... \& Tsouris, C. (2011). Sustainable development and energy geotechnology Potential roles for geotechnical engineering. KSCE Journal of Civil Engineering, 15(4), 611-621. https:// doi.org/10.1007/s12205-011-0102-7

Godio, A., Strobbia, C., \& De Bacco, G. (2006). Geophysical characterisation of a rockslide in an alpine region. Engineering Geology, 83(1-3), 273-286. https://doi.org/10.1016/j.enggeo.2005.06.034

Griffiths, D. H., \& Barker, R. D. (1993). Two-dimensional resistivity imaging and modelling in areas of complex geology. Journal of Applied Geophysics, 29(3-4), 211-226. https://doi.org/10.1016/0926-9851(93)90005-J

Ingeman-Nielsen, T., Tomaškovičová, S., \& Dahlin, T. (2016). Effect of electrode shape on grounding resistances - Part 1: The focus-one protocol. Geophysics, 81(1), WA159-WA167. https://doi.org/10.1190/ GEO2015-0484.1

Loke, M. H. (2018). Tutorial: 2-D and 3-D electrical imaging surveys. Geotomosoft.

Loke, M. H., Acworth, I., \& Dahlin, T. (2003). A comparison of smooth and blocky inversion methods in 2D electrical imaging surveys. Exploration Geophysics, 34(3), 182-187. https://doi.org/10.1071/EG03182

Loke, M. H., \& Barker, R. D. (1996). Rapid least-squares inversion of apparent resistivity pseudosections by a quasiNewton method1. Geophysical Prospecting, 44(1), 131-152. https://doi.org/10.1111/j.1365-2478.1996. tb00142.x

Loke, M. H., Chambers, J. E., Rucker, D. F., Kuras, O., \& Wilkinson, P. B. (2013). Recent developments in the direct-current geoelectrical imaging method. Journal of Applied Geophysics, 95, 135-156. https:// doi.org/10.1016/j.jappgeo.2013.02.017

Martínez-Moreno, F. J., Pedrera, A., Ruano, P., Galindo-Zaldívar, J., Martos-Rosillo, S., González-Castillo, L., Sánchez-Úbeda, J. P., \& Marín-Lechado, C. (2013). Combined microgravity, electrical resistivity tomography and induced polarization to detect deeply buried caves: Algaidilla cave (Southern Spain). Engineering Geology, 162, 67-78. https://doi.org/10.1016/j.enggeo.2013.05.008

Muhammad, S. B., \& Saad, R. (2018). Linear regression models for estimating true subsurface resistivity from apparent resistivity data. Journal of Earth System Science, 127(5), Article 64. https://doi.org/10.1007/ s12040-018-0970-z

Pando, L., Pulgar, J. A., \& Gutiérrez-Claverol, M. (2013). A case of man-induced ground subsidence and building settlement related to karstified gypsum (Oviedo, NW Spain). Environmental Earth Sciences, 68(2), 507-519. https://doi.org/10.1007/s12665-012-1755-3 
Pradhan, B., \& Lee, S. (2010). Delineation of landslide hazard areas on Penang Island, Malaysia, by using frequency ratio, logistic regression, and artificial neural network models. Environmental Earth Sciences, 60(5), 1037-1054. https://doi.org/10.1007/s12665-009-0245-8

Rucker, D. F., Crook, N., Glaser, D., \& Loke, M. H. (2012). Pilot-scale field validation of the long electrode electrical resistivity tomography method. Geophysical Prospecting, 60(6), 1150-1166. https://doi. org/10.1111/j.1365-2478.2011.01039.x

Szalai, S., Koppán, A., \& Szarka, L. (2008). Effect of positional inaccuracies on multielectrode results. Acta Geodaetica et Geophysica Hungarica, 43(1), 33-42. https://doi.org/10.1556/AGeod.43.2008.1.3

Tan, B. K. (1994). Engineering properties of granitic soils and rocks of Penang Island, Malaysia. Bulletin of the Geological Society of Malaysia, 35(July), 69-77. https://doi.org/10.7186/bgsm35199408

Thabit, J. M., \& Khalid, F. H. (2016). Resistivity imaging survey to delineate subsurface seepage of hydrocarbon contaminated water at Karbala Governorate, Iraq. Environmental Earth Sciences, 75(1), Article 87. https:// doi.org/10.1007/s12665-015-4880-y

Uhlemann, S., Chambers, J., Falck, W., Tirado Alonso, A., Fernández González, J., \& Espín de Gea, A. (2018). Applying electrical resistivity tomography in ornamental stone mining: Challenges and solutions. Minerals, 8(11), Article 491. https://doi.org/10.3390/min8110491

Zhou, B., \& Dahlin, T. (2003). Properties and effects of measurement errors on 2D resistivity imaging surveying. Near Surface Geophysics, 1(3), 105-117. https://doi.org/10.3997/1873-0604.2003001 
